\title{
On the role of homologous sequences in chromosomal rearrangements
}

\author{
Britta Swebilius Singer \\ Department of Molecular, Cellular, and Developmental Biology, University of Colorado, Boulder, Colorado 80309 USA
}

\begin{abstract}
Deletions and other chromosomal rearrangements can be generated by recombination between repeated sequences. It has been shown in a number of systems that the probability of exchange or gene conversion decreases with increasing distance between repeats. This paper examines the question of how repeats find each other, using deletion formation in bacteriophage $\mathrm{T} 4$ as a model system. Homologous sequences adjacent to the repeats can either stimulate or inhibit recombination, depending on their orientation. I present evidence that the spatial separation between repeats is the key determinant of the distance dependence and conclude that adjacent homologous sequences affect recombination by aligning chromosomes so as to position the recombining sites either closer together or farther apart. Analogous examples of apparent 'targeting' by homologous sequences in eukaryotes and other prokaryotes are noted.
\end{abstract}

[Key Words: Homologous sequences; recombination; chromosomal rearrangements]

Received July 15, 1988; revised version accepted October 19, 1988.

Chromosomal rearrangements that involve direct repeats have great significance in evolution. Deletions, duplications, inversions, and translocations all involve repeats and can arise during recombination. Nonallelic gene conversion among homologous genes (or pseudogenes) has been demonstrated in a number of systems (e.g., Slightom et al. 1980; Ernst et al. 1982; Flavell et al. 1986; Geliebter et al. 1986; Heyer et al. 1986; Powers and Smithies 1986; Reynaud et al. 1987). Exchange is also possible between nonhomologous genes. The tailfiber genes 37 and 38 of the T-even phages confer host range specificity and are highly polymorphic among these phages. Riede (1986) demonstrated exchange between T4 gene 38 and two nonhomologous T4 genes. Moreover, extensive sequence similarity has been found between this region in T4 and regions in the $\lambda$ and Escherichia coli chromosomes (George et al. 1983; Riede et al. 1985; Michel et al. 1986). Shinedling et al. (1987) have noted a repeat-directed mutational mechanism that they term 'sequence conversion.' These observations suggest that nontraditional exchange or conversion of genetic material may be fairly common, even without the mediation of transposons and other mobile DNA.

Roeder et al. (1984) demonstrated that the movement of Ty elements in yeast is less likely the greater the distance between the repeats. Dvořák et al. (1987) showed that the homogenization of multigene families is also subject to distance dependence. It has been shown (Singer and Westlye 1988) that the distance between repeats is one important parameter of deletion formation in bacteriophage T4; the farther apart the repeats are, the less frequently the deletion occurs. This is also true in $E$. coli (Albertini et al. 1982). It seems likely that all in- terchromosomal rearrangements involving repeats will be subject to distance dependence.

This paper examines the question of distance dependence, using deletion formation in bacteriophage $\mathrm{T} 4$ as a model system. Earlier results (Singer and Westlye 1988) indicated that intermolecular recombination accounts for much deletion formation in T4. It seemed likely that the balance of deletions might arise by slipped mispairing during DNA synthesis, as proposed by Efstratiadis et al. (1980), Albertini et al. (1982), and DasGupta et al. (1987). In this pathway, at least two factors contribute to the decrease in deletion frequency that is attributable to increased distance between repeats. In slipped mispairing, the repeats are physically tethered; the closer the repeats are, the more likely their interaction. Moreover, the slipped mispairing model requires that both repeats exist simultaneously in singlestranded DNA, a condition that is more likely when the repeats are closer.

Is distance between repeats a factor when deletions arise during recombination? If so, why? Deletion formation during recombination requires that left and right repeats find each other prior to exchange. If left and right repeats on different chromosomes find each other by random collisions, then why should deletion formation decrease as a function of distance? To examine these questions, I used biparental crosses in which one repeat is on one chromosome and the other is on a different chromosome (Fig. 1). In this configuration, only recombination can generate deletions. By manipulating the spacer sequences, it is possible to probe the roles of adjacent homologous and heterologous DNA on deletion formation. 


\section{Results and discussion}

\section{Distance dependence in deletion formation}

To discover whether deletion formation through recombination is also subject to distance dependence, I inserted varying sizes of spacer DNA adjacent to left and right repeats and carried out biparental crosses (Fig. 1A-C). The results (Table 1) show that increasing the size of the homologous spacer DNA reduces the frequency of the recombination that yields the deletion decreases.

\section{The competition model}

Recombination to yield a deletion requires alignment between the two repeats. This alignment is prevented when there is alignment in the spacer region (cf. Figs. 1C and 2A). Thus, increasing the probability of alignment in the spacer (by greater length of spacer) would be expected to decrease the deletion frequency.

To test this 'competition' model, I compared deletion frequencies in crosses that have homologous spacers with those that have nonhomologous spacers. In crosses with heterologous spacers, potential inhibition generated by homologous spacers is removed and the recombination frequencies should be increased. Table 2 shows the results of crosses with heterologous spacers. A comparison of these data with the results of Table 1 shows that nonhomologous spacer sequences inhibit recombination less than homologous spacer sequences. When the nonhomologous spacers are approximately the same size, e.g., 332 and $341 \mathrm{bp}$, the recombination frequencies are higher $\left(\sim 10^{-4}\right)$ than in the corresponding crosses in which the spacer DNAs are homologous $\left(2 \times 10^{-5}\right.$ to $5 \times 10^{-5}$ ). This result is consistent with the competition model, but the effect, if any, is small.

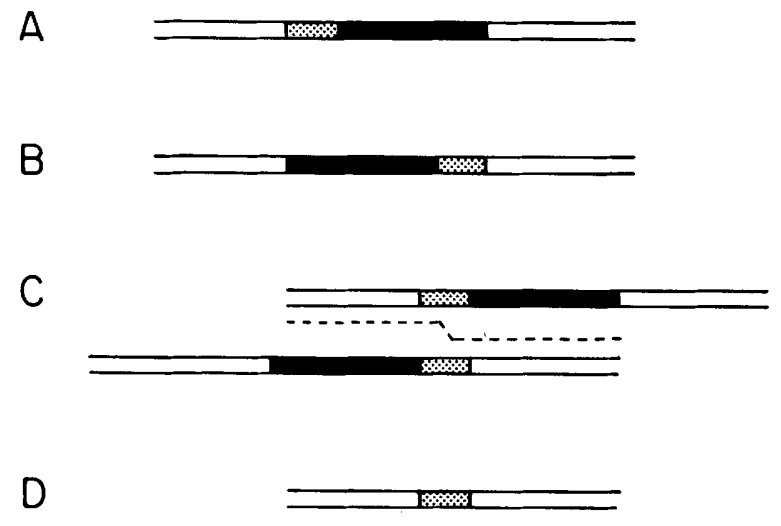

Figure 1. The parents in biparental crosses are shown schematically in $A$ and $B .(A)$ The parent with the left repeat; $(B)$ the parent with the right repeat; $|C|$ the alignment required to generate the deletion (dashed line); $(D)$ the deletion chromosome. The phage with this chromosome is pseudo-wild; all of the other chromosomes depicted confer the mutant phenotype. Thus, it is possible to use selective plating conditions to measure deletion/recombination frequencies.
Table 1. Influence of size of homologous spacer on recombination frequency

\begin{tabular}{ccc}
\hline Size of spacer & \multicolumn{2}{c}{ Frequency of recombination $\left(\times 10^{5}\right)$} \\
\hline 79 & 17 & $( \pm 2)$ \\
332 & 1.9 & $( \pm 0.3)$ \\
341 & 5.1 & $( \pm 1.0)$ \\
1698 & $0.52( \pm 0.3)$ \\
\hline
\end{tabular}

The crosses are diagramed in Fig. 1. Identical spacer DNA is inserted adjacent to the repeat in both chromosomes. Four base pairs separate the spacer from the repeat in the chromosome with the right repeat. The spacer abuts the repeat in the other chromosome (see Table 5). The frequencies reported are the fraction of total progeny phage that are able to grow on the nonpermissive host. Because of the analogy to deletion formation, this frequency has not been doubled, although it seems likely that the actual recombination frequency is twice the number recorded. The frequencies reported are the averages $( \pm \mathrm{SEM})$ of at least three separate crosses performed with different lysates. The strains used for these crosses have GC-rich repeats and are specified in Table 7.

\section{The importance of spatial separation between repeats}

The competition model predicts that all crosses with nonhomologous spacers should have similar deletion frequencies because all have the same potential for aligning in the $\mathrm{T} 4$ chromosome and in the repeats. This is not the case. When the heterologous spacers are of different sizes, the extent of recombination is determined largely by the length of the shorter of the two spacer DNAs (Table 2B). When strains with 79-bp spacer sequences are crossed to strains with inserts ranging in size from 332 to $1698 \mathrm{bp}$, the recombination frequencies are all about the same. The highest recombination frequencies are obtained when one of the parents has no spacer insert (Table $2 \mathrm{~B}$ ). This suggests that the spatial separation between the repeats is important.

If alignment in the spacer region is important, inverting the homologous spacer DNA in one of the parents should have the effect of bringing the repeats closer together. This is diagramed in Figure 2D. In this drawing, the lower chromosome has been flipped to allow alignment in the spacer DNAs. Note that in this configuration, the direct repeats (as well as the overall chromosomes/ are oriented in opposite directions. The 'spatial separation' hypothesis predicts that crosses in which the direct repeats are very close to each other should yield more deletions than when the repeats are farther apart. In every case, recombination frequencies are higher in 'opposite orientation' crosses than in the corresponding 'same orientation' crosses (Table 3). Table 3 also shows results of crosses with AT-rich repeats. As noted earlier (Singer and Westlye 1988), for a given length of spacer, AT-rich repeats are far less likely to yield deletions than GC-rich repeats However, both kinds of crosses are influenced in the same way by homologous sequences.

A further test of the spatial separation hypothesis is provided by crosses in which one of the parents has ex- 
SAME ORIENTATION

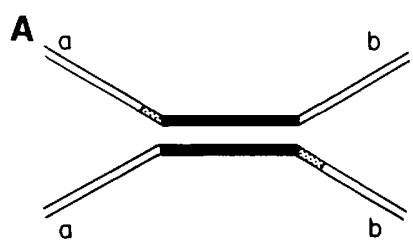

Figure 2. The left panel $(A, B, C)$ depicts alignment of chromosomes in the spacer regions in same orientation crosses. The right panel $(D, E, F)$ shows the analogous pairing for opposite orientation crosses. Note that the lower chromosomes in the right panel are flipped to allow alignment in the spacer. $(A$ and $D$ ) The basic same and opposite orientation crosses. $(B$ and $E)$ Interrupter DNA has been inserted between the spacer and the repeat of the top chromosome. $(C$ and $F)$ The interrupter DNA has been inserted at the other end of the spacer. The T4 chromosome is linear but circularly permuted. Figs. $2-5$ show chromosomes with physical ends far from the region of repeats and inserts, statistically the most probable configuration. Doermann and Parma (1967) have shown that recombination is enhanced at the ends of chromosomes but that should not affect the results or interpretation presented here (D. Parma, pers. comm.).
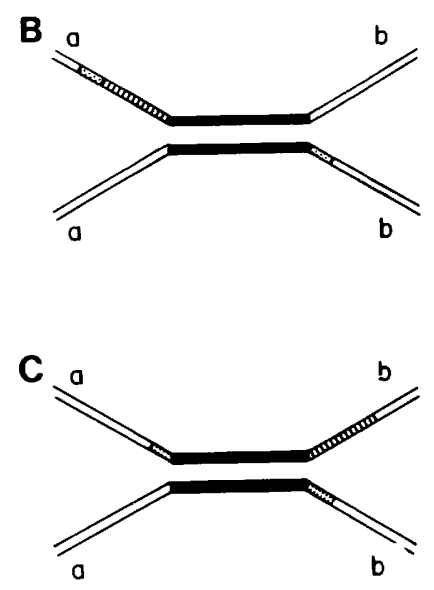

OPPOSITE ORIENTATION
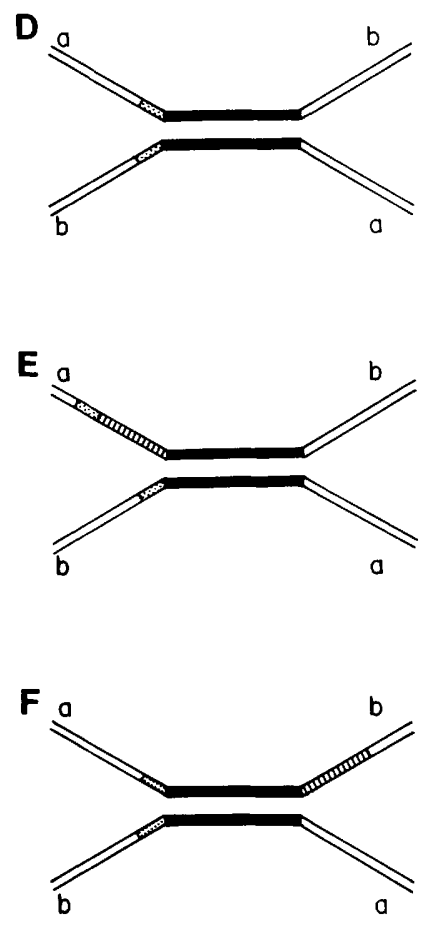

traneous nonhomologous DNA (interrupter DNA) inserted between the repeat and the homologous spacer DNA. In opposite orientation crosses, the interrupter substantially increases the distance between repeats /cf. Fig. $2 \mathrm{D}, \mathrm{E}$ ). As expected, the deletion frequency is reduced in these crosses (see Table 4A). On the other hand, it seemed likely that putting an interrupter between the repeat and the spacer in the same orientation crosses would have little or no effect on deletion frequencies because the repeats are still held apart by the spacer DNA (see Fig. 2B). Table 4A shows that deletion frequencies in these crosses are unaffected, as expected.

As a control, I also inserted interrupter sequences at the other end of the spacer, away from the repeat (Fig. $2 \mathrm{C}, \mathrm{F})$. In this case, the interrupter sequences do not influence the spatial separation between repeats /cf. Fig. $2 \mathrm{C}, \mathrm{F})$. Table 4 shows that interrupter sequences have an influence on the deletion frequencies only when they are between repeat and spacer in opposite orientation crosses, as predicted by the spatial separation hypothesis.

\section{Role of recombination pathways}

Although the chief focus of these experiments was to probe the structural features that influence recombination, that yields deletions, it was also important to determine the impact of phage mutations that influence general recombination on these crosses. The requirement for various recombination functions in same orientation and opposite orientation crosses was examined.
The mutations tested are listed in Experimental procedures. In every case, recombination defects affected both crosses similarly (not shown).

\section{A kinetic scheme}

As noted previously, in all of these crosses, the only alignment that yields the deletion is the alignment shown in Figure 1C, with the two repeats poised for a crossover. This alignment is less probable than alignment in the spacer because the repeat is shorter than the spacer. Moreover, the two alignments are mutually exclusive. Alignment in the spacer inhibits deletion formation in the same orientation crosses (Fig. 2A), whereas the comparable alignment in opposite orientation crosses enhances deletion formation (Fig. 2D). The competition model suggests that the reason for the inverse relationship between spacer size and deletion frequency in same orientation crosses is that the larger the spacer, the more probable the inhibitory alignment. If so, increasing the size of the spacer in opposite orientation crosses should increase the recombination frequency. This is not the case; the frequency of recombination in opposite orientation crosses is independent of the size of the spacer (Table 3). This apparent paradox is resolved if dissociation of the aligned segments (rather than alignment) is the limiting step in same orientation and opposite orientation crosses, as discussed below.

There is ample evidence to suggest that doublestranded DNA in vivo is a flexible random coil (e.g., Hagerman 1981). The random encounter of one very short 
Table 2. Recombination frequencies in crosses with nonhomologous spacers

A. Crosses in which the lengths of nonhomologous spacer DNA are similar. A strain with a left repeat and a 341-bp spacer was crossed to strains with a right repeat and a 332-bp or 411-bp spacer /results shown in second column). Similarly, a strain with a right repeat and a $341-\mathrm{bp}$ spacer was crossed with strains with a left repeat and a 332-bp or 411-bp spacer (shown in third column).

\begin{tabular}{lcc}
\hline $\begin{array}{l}\text { Size of spacer } \\
\text { adjacent to other } \\
\text { repeat }(\mathrm{bp})\end{array}$ & \multicolumn{2}{c}{$\begin{array}{l}\text { Recombination frequency }\left(\times 10^{5}\right) \\
\text { when 341-bp spacer is adjacent to }\end{array}$} \\
\cline { 2 - 3 } 332 & left repeat & right repeat \\
411 & $10( \pm 1)$ & $12 \quad( \pm 3)$ \\
\hline
\end{tabular}

B. Crosses in which the lengths of nonhomologous DNA are different. As above, for each series of crosses (except the first), a spacer of a given size (reference spacer) was inserted adjacent to either the left or the right repeat. By this terminology, the 341 -bp spacer used in the crosses above is the reference spacer. In the first set of crosses, the spacer is the 4 bp mentioned in Table 1.

\begin{tabular}{|c|c|c|c|}
\hline \multirow{2}{*}{$\begin{array}{l}\text { Size of } \\
\text { reference } \\
\text { spacer (bp) }\end{array}$} & \multirow{2}{*}{$\begin{array}{l}\text { Size of spacer } \\
\text { adjacent to } \\
\text { other repeat }(\mathrm{bp})\end{array}$} & \multicolumn{2}{|c|}{$\begin{array}{l}\text { Recombination frequency } \\
\left(\times 10^{5}\right) \text { when reference } \\
\text { spacer is adjacent to }\end{array}$} \\
\hline & & left repeat & right repeat \\
\hline \multirow[t]{5}{*}{ none } & 79 & not done & $( \pm 10)$ \\
\hline & 332 & not done & $( \pm 40)$ \\
\hline & 341 & not done & $( \pm 70)$ \\
\hline & 411 & not done & $( \pm 20)$ \\
\hline & 1698 & not done & $( \pm 10)$ \\
\hline \multirow[t]{4}{*}{79} & 332 & $15 \quad( \pm 5)$ & $( \pm 5)$ \\
\hline & 341 & $24 \quad( \pm 5)$ & $31 \quad( \pm 9)$ \\
\hline & 673 & $20 \quad( \pm 6)$ & not done \\
\hline & 1698 & $12( \pm 3)$ & $23| \pm 3|$ \\
\hline \multirow[t]{5}{*}{1698} & 79 & $23 \quad( \pm 3)$ & $12( \pm 3)$ \\
\hline & 332 & $5.1( \pm 0.8)$ & $4.0( \pm 0.7)$ \\
\hline & 341 & $13( \pm 5)$ & $7.3( \pm 1.6)$ \\
\hline & 411 & $6.0( \pm 0.7)$ & $3.3( \pm 0.7)$ \\
\hline & 673 & $2.0( \pm 0.3)$ & not done \\
\hline
\end{tabular}

The conditions of the crosses are as in Table 1 , except that the spacer DNA differs between the two parents. In these crosses, alignment in the spacer is not possible (see Fig. 5). All of the strains used in these experiments have GC-rich repeats.

piece of DNA with another of identical (or similar) sequence (whether by tracking or facilitated diffusion, as indicated by Gonda and Radding 1986) must be an early step in recombination. Studies in vitro demonstrate that this initial alignment can be extended (if there is homology) in a three- or four-strand paranemic or plectonemic structure for perhaps thousands of base pairs (McGavin 1971; Wilson 1979; Bianchi et al. 1983; Howard-Flanders et al. 1984; Riddles and Lehman 1985; Christiansen and Griffith 1986; Schutte and Cox 1987). Although I am aware of no experimental demonstrations, it seems likely that this three- or four-stranded structure (with bound proteins) is quite rigid. If so, then the repeats are held apart from each other in the same orientation crosses to an extent that should be roughly proportional to the size of the insert.

Figure 3 shows probable steps involved in deletion formation in same orientation crosses. Figure $3 \mathrm{~A}$ shows DNA in its random coil configuration. Initial alignment may involve either the direct repeats (Fig. $3 \mathrm{~B}$ ) or the spacers (Fig. 3C). (Alignment involving the rest of the chromosome is discussed below.) Initial alignment between the repeats (Fig. 3B) is improbable, and it seems likely that chromosomes involved in such a pairing would return readily to the unaligned configuration (Fig. 3A). This extent of DNA is below the minimum site size required for mainstream recombination in T4 (Singer et al. 1982). The first step in alignment must involve an encounter between very few base pairs. Thus, initial recognition in the spacer region is more probable than initial recognition in the repeat sequence because there are more base pairs in the spacer. Moreover, the extent of DNA available for alignment is greater. Chromosomes aligned in the spacer (Fig. $3 \mathrm{C}$ ) are very unlikely to come apart. The recombination machinery will hold them together until there is resolution of the recombination intermediate. I suggest, however, that occasionally this alignment does fall apart. As the structure dissociates, the repeats are briefly in proximity (Fig. 3D). The distance between direct repeats is proportional to the length of the spacer. If the repeats find each other, they can align (as shown in Fig. 3B), this configuration is the prerequisite for deletion formation. Here, again, alignment between spacers is a more likely outcome of Figure $3 \mathrm{D}$ than is alignment between repeats. Recombination within the spacer, either with or without exchange of flanking chromosome, would tend to put the DNA back into the state depicted in Figure 3A.

Figure 4 shows probable steps involved in deletion for-

Table 3. Comparison of recombination frequencies in opposite orientation and same orientation crosses

\begin{tabular}{|c|c|c|c|c|c|}
\hline \multirow{3}{*}{$\begin{array}{l}\text { Base composition } \\
\text { repeat } \\
\text { GC rich }\end{array}$} & \multirow{3}{*}{$\frac{\begin{array}{l}\text { Size of } \\
\text { spacer }(b p)\end{array}}{79}$} & \multicolumn{4}{|c|}{ Frequency of recombination $\left(\times 10^{5}\right)$} \\
\hline & & \multicolumn{2}{|c|}{$\begin{array}{l}\text { same orientation } \\
\text { crosses }\end{array}$} & \multicolumn{2}{|c|}{$\begin{array}{l}\text { opposite orientation } \\
\text { crosses }\end{array}$} \\
\hline & & 17 & $( \pm 2)$ & 34 & $( \pm 2)$ \\
\hline GC rich & 332 & 1.9 & $( \pm 0.3)$ & 43 & $( \pm 8)$ \\
\hline GC rich & 1698 & 0.52 & $( \pm 0.3)$ & 15 & $( \pm 5)$ \\
\hline AT rich & 332 & 0.023 & $( \pm 0.004)$ & 0.17 & $( \pm 0.02)$ \\
\hline AT rich & 332 & 0.023 & $( \pm 0.003)$ & 0.22 & $( \pm 0.05)$ \\
\hline
\end{tabular}

The crosses are diagramed in Fig. 2. Conditions are the same as in Table 1, except that in one half of the crosses, the spacer DNA of one chromosome is inverted relative to the other. The same orientation results shown here are from Table 1. 
Table 4. Influence of interrupter

A. Recombination frequency $\left(\times 10^{5}\right)$ in crosses in which the interrupter is between repeat and spacer (see Fig. 2B,E).

\begin{tabular}{|c|c|c|c|c|c|c|c|c|c|}
\hline \multirow{2}{*}{$\begin{array}{l}\text { Base } \\
\text { composition } \\
\text { of repeat }\end{array}$} & \multirow{2}{*}{$\begin{array}{l}\text { Size of spacer } \\
\text { and interrupter } \\
\text { (bp) }\end{array}$} & \multicolumn{4}{|c|}{ Same orientation crosses } & \multicolumn{4}{|c|}{ Opposite orientation crosses } \\
\hline & & \multicolumn{2}{|c|}{$\begin{array}{l}\text { with } \\
\text { interrupter }\end{array}$} & \multicolumn{2}{|c|}{$\begin{array}{l}\text { without } \\
\text { interrupter }\end{array}$} & \multicolumn{2}{|c|}{$\begin{array}{l}\text { with } \\
\text { interrupter }\end{array}$} & \multicolumn{2}{|c|}{$\begin{array}{l}\text { without } \\
\text { interrupter }\end{array}$} \\
\hline AT rich & $332(79)$ & 0.023 & $( \pm 0.003)$ & 0.023 & $( \pm 0.004)$ & 0.031 & $( \pm 0.003)$ & 0.17 & $( \pm 0.02)$ \\
\hline AT rich & $332(79)$ & 0.046 & $( \pm 0.022)$ & 0.023 & $( \pm 0.003)$ & 0.053 & $( \pm 0.008)$ & 0.22 & $i \pm 0.05)$ \\
\hline GC rich & $332(79)$ & \multicolumn{2}{|c|}{ not done } & 1.9 & $( \pm 0.03)$ & 4.4 & $( \pm 1.3)$ & 43 & $( \pm 8)$ \\
\hline $\mathrm{GC}$ rich & $79(332)$ & 20 & $( \pm 1)$ & 17 & $( \pm 2)$ & 19 & $( \pm 4)$ & 34 & $( \pm 2)$ \\
\hline
\end{tabular}

B. Recombination frequency $\left(\times 10^{5}\right)$ in crosses in which the interrupter is at the other edge of the spacer (distal to repeat) (see Fig. 2C,F).

\begin{tabular}{|c|c|c|c|c|c|c|c|c|c|}
\hline \multirow{2}{*}{$\begin{array}{l}\text { Base } \\
\text { composition } \\
\text { of repeat }\end{array}$} & \multirow{2}{*}{$\begin{array}{l}\text { Size of spacer } \\
\text { and interrupter } \\
\qquad|\mathrm{bp}\rangle\end{array}$} & \multicolumn{4}{|c|}{ Same orientation crosses } & \multicolumn{4}{|c|}{ Opposite orientation crosses } \\
\hline & & \multicolumn{2}{|c|}{$\begin{array}{l}\text { with } \\
\text { interrupter }\end{array}$} & \multicolumn{2}{|c|}{$\begin{array}{l}\text { without } \\
\text { interrupter }\end{array}$} & \multicolumn{2}{|c|}{$\begin{array}{l}\text { with } \\
\text { interrupter }\end{array}$} & \multicolumn{2}{|c|}{$\begin{array}{l}\text { without } \\
\text { interrupter }\end{array}$} \\
\hline AT rich & $332(79)$ & 0.026 & $( \pm 0.002)$ & 0.023 & $( \pm 0.004)$ & 0.23 & $( \pm 0.10 \mid$ & 0.17 & $( \pm 0.02)$ \\
\hline $\mathrm{AT}$ rich & $332(79)$ & 0.035 & $( \pm 0.009)$ & 0.023 & $( \pm 0.003)$ & 0.16 & $( \pm 0.01)$ & 0.22 & $( \pm 0.05)$ \\
\hline GC rich & $332(79)$ & 1.3 & $( \pm 0.4)$ & 1.9 & $( \pm 0.3)$ & 33 & $| \pm 9|$ & 43 & $\{ \pm 8\}$ \\
\hline GC rich & $79(332)$ & 9.4 & $( \pm 1.4)$ & 17 & $( \pm 2)$ & 31 & $( \pm 3)$ & 34 & $( \pm 2)$ \\
\hline
\end{tabular}

a Interrupter DNA of the length indicated in parentheses was inserted adjacent to spacer DNA. Results for crosses of strains without interrupter sequences are from Table 3.

mation in opposite orientation crosses. Figure 4, $\mathrm{A}$ and $B$, is analogous to Figure $3, A$ and $B$. Figure $4, C$ and $D$ is similar to Figure $3, \mathrm{C}$ and $\mathrm{D}$, with a few exceptions. In Figure $4 \mathrm{C}$, the extent of the aligned DNA is limited to the size of the spacer because the adjacent regions are nonhomologous (because of the flipping of the chromosomes). Although the repeats in Figure 4D are close together, they are in opposite orientation and thus must rotate prior to aligning, as in Figure 4B. This is probably less of a consideration in the three-dimensional milieu of the cell than it appears to be on the printed page. Figure 4E shows an additional outcome of Figure 4C. In Figure 4E, dissociation of only the left-hand end of the aligned structure should allow alignment within the repeats. (This consideration suggests that there may be an ideal length of interrupter that would enhance deletion formation in opposite orientation crosses.) In any case, Figure 4 suggests that the formation of the structure aligned in the spacer is not the limiting step. The slow step is the rearrangement of that structure to allow recombination within the repeats.

The spacers and direct repeats that were inserted constitute a very small fraction of the T4 chromosome $(\leqslant 1 \%)$. Thus, any discussion of alignment must consider the consequences of aligning in the nonengineered portions of the chromosome. In crosses with nonhomologous spacer, these regions of the chromosomes are the only DNA segments available for alignment (in addition to the repeats themselves). Figure 5 shows the case of crosses in which the spacers are nonhomologous. These drawings show probable steps that lead to deletion formation when the shorter spacer is adjacent to the left repeat. The left panel shows the consequences of aligning in the region of the T4 chromosome to the left of the spacers and repeats (i.e., aligning in the 5 ' end of
IIIB and the region clockwise on the T4 genetic map). The right panel is analogous, except that alignment is in the part of the T4 chromosome to the right of the spacers and repeats (downstream IIIB and the region counterclockwise on the T4 genetic map). In the right panel, the distance between the repeats is determined by the length of the shorter spacer; this is the alignment that determines deletion frequency (Table 2). The alignment shown in the left panel makes a negligible contribution to deletion formation.

Chromosomes involved in opposite orientation crosses can also align, as shown in Figure 5. The significance of this alignment, relative to the alignment in the spacer (Figs. 2D and $4 \mathrm{C}$ ) can be determined by comparing the nonhomologous spacer data from Table 2 with the opposite orientation cross data of Table 3. When the spacer is as short as $332 \mathrm{bp}$, the opposite orientation crosses yield more deletions than the comparable crosses with nonhomologous spacers. This indicates that even a segment of DNA as short as $332 \mathrm{bp}$ can, with high probability, direct the conjunction of repeats such that a chromosomal rearrangement follows. This stimulation of recombination may be termed 'targeting.'

\section{Examples in other systems}

The results presented here indicate that the spatial separation between repeats is a key determinant of their finding each other for recombination. Adjacent sequences that do not participate in the recombinational exchange can influence the probability of recombination within the repeats by increasing or decreasing the space between repeats. These experiments were done in T4; comparable examples are found in other systems. As noted above, Roeder et al. (1984) found that recombina- 
A

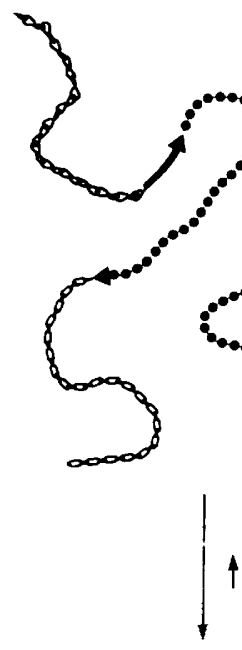

C

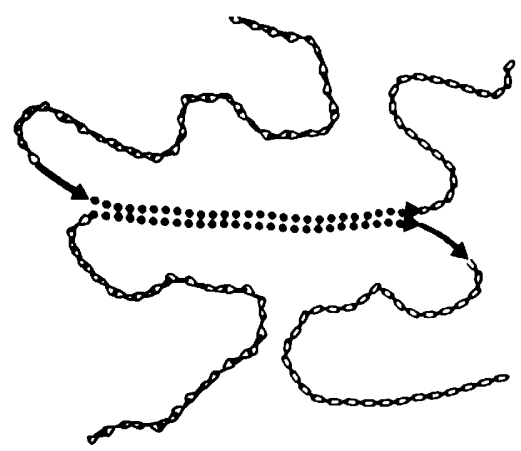

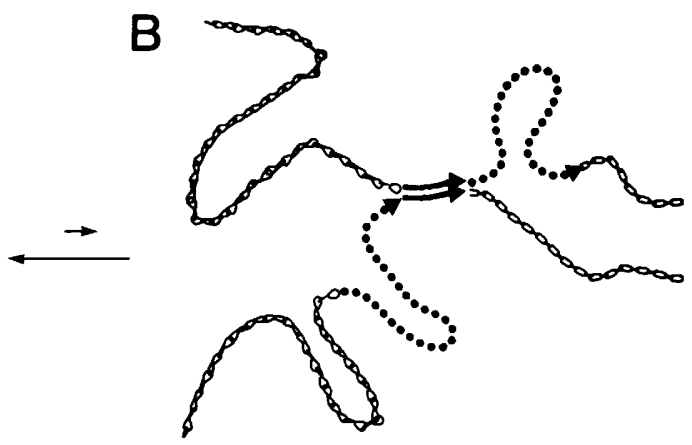

$\uparrow \downarrow$

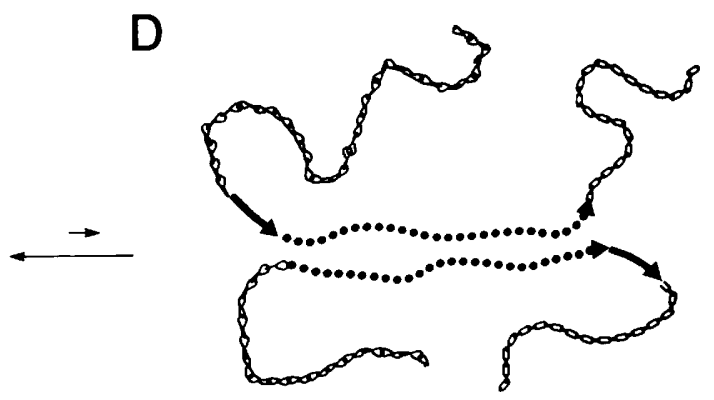

Figure 3. Probable steps in deletion formation in same orientation crosses. Two chromosomes are depicted in each panel. $(A)$ The chromosome on the left represents the chromosome with the left repeat, and the chromosome on the right has the right repeat. One kind of chain represents the region of the T4 genome to the left of the inserted DNA in each chromosome, and a different kind of chain is used for the region of the T4 chromosome to the right of the inserted DNA. The repeats are represented by short pieces of rope; the spacers are represented by beads on a string. Arrowheads within the chromosomes indicate the orientations of repeats and spacers. The sizes of the arrows between the pictures represent guesses as to relative frequency; in some cases, the relative frequency probably depends on the size of the spacer. $(A)$ DNA with no segments aligned. $(B)$ The repeats are aligned this is equivalent to Fig. 1C.) $(C)$ The spacers are aligned (equivalent to Fig. 2A). (D) The instant after the alignment shown in $C$ has 'melted' and before the chromosomes have diffused away.

tion between Ty elements in Saccharomyces cerevisiae is a function of the distance between the Ty elements. Dvořák et al. (1987) showed that the patterns of sequences of the nontranscribed spacers of rRNA genes in a number of species are most consistent with the hypothesis that homogenization among these sequences proceeds by distance-dependent gene conversion. In these cases, homologous sequences between repeats decrease the probability of recombination.

In other instances, homologous sequences can increase the probability of recombination. Anca Segall and John Roth (pers. comm.) have demonstrated this kind of enhancement in Salmonella typhimurium. They found that recombination between two lac operons inserted in nonhomologous regions of the chromosome is enhanced when both adjoin intact mu sequences. This stimulation cannot be accounted for by branch migration since several kilobases separate one recombining sequence from the adjoining mu sequence.
The strategy of using homologous DNA to direct chromosomal rearrangements has been used by trypanosomes. In these organisms, nonallelic gene conversion is responsible for surface antigen variation after infection. Only one telomere-linked gene copy is expressed, although $>100$ different surface antigen genes are found within the genome. The frequency with which the expressed gene is replaced by another is determined by homologous sequences that flank the expressed gene and the replacement gene. In between these homologous sequences, the structural genes have low homology (for review, see Pays 1985). Similar targeting may be used by Neisseria gonorrhoeae to effect pilus antigenic variation (Haas and Meyer 1986). In this case, incomplete genes in the major silent locus contain sequence information for the semivariable and hypervariable domains of pilin. These sequences are separated by 39 -bp repeats that are also found in the expression loci. Other sequences are conserved between silent and expression loci as well. It 
A
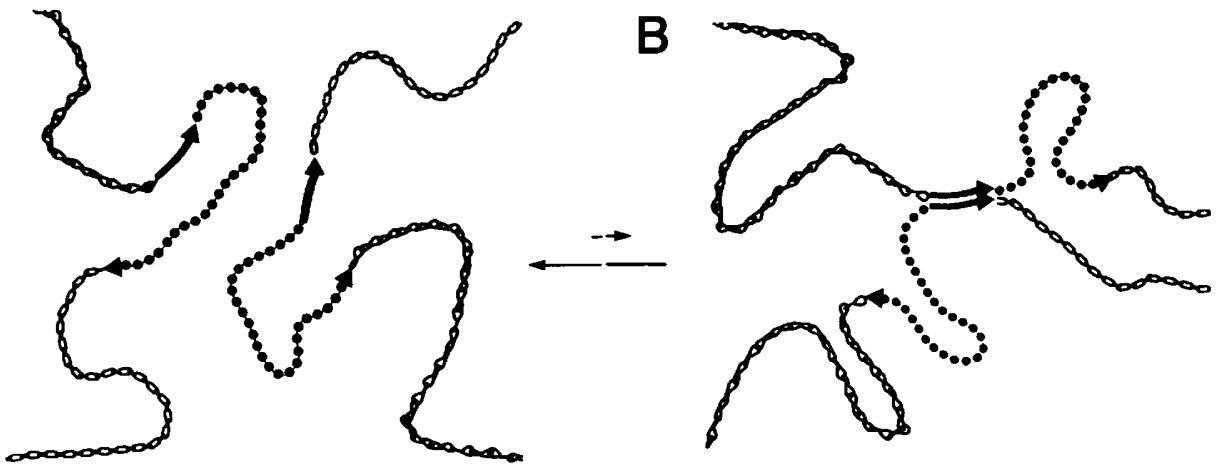

C<smiles>CC1([Tl])CCCCC1</smiles>
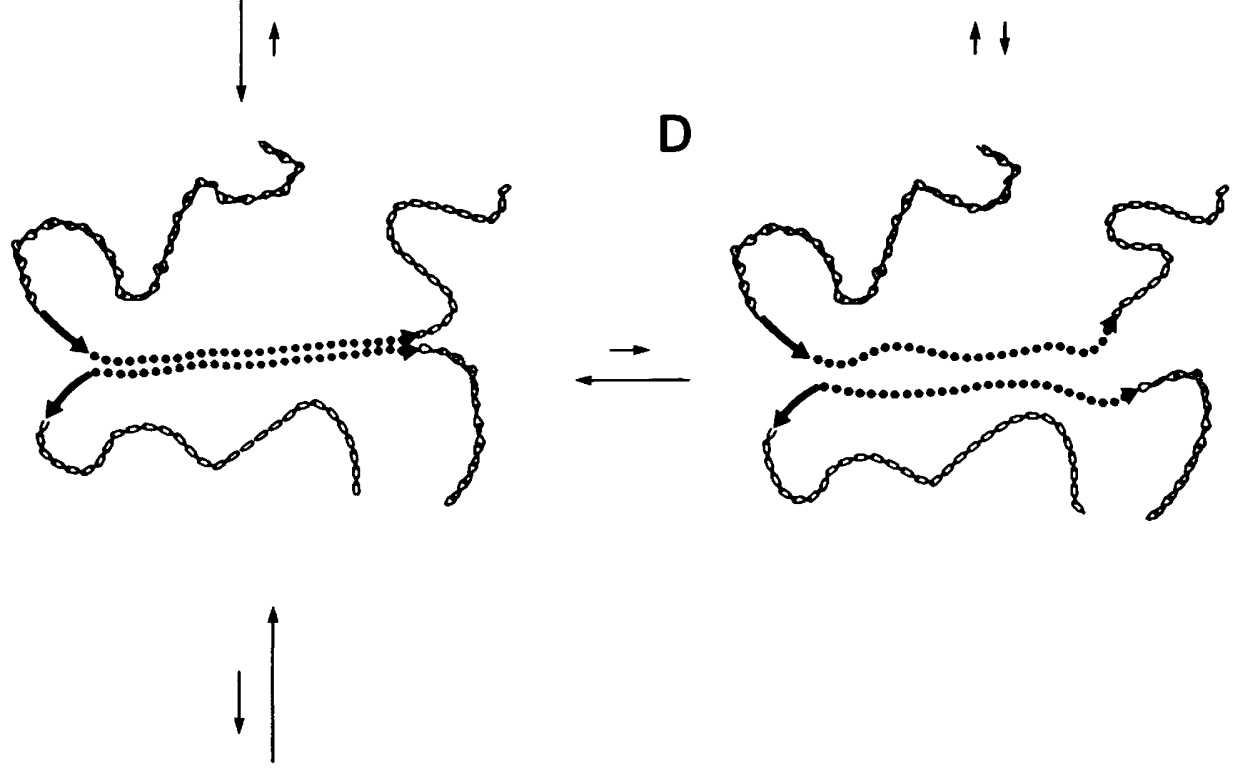

$E$

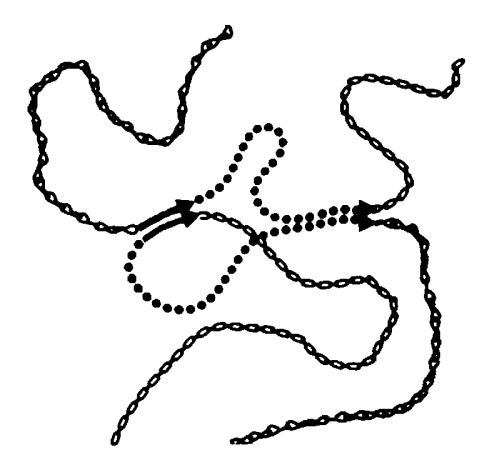

Figure 4. Probable steps in deletion formation in opposite orientation crosses. Various parts of the chromosomes are represented by the same devices as in Fig. 3 ; however, the orientation of the spacer of the chromosome on the right has been inverted. $(A-D)$ Analogous to $A-D$ in Fig. 3 (except that the alignment in $C$ is analogous to Fig. 2D). $(E)$ The alignment between repeats that is made possible by melting no more than the left end of the alignment depicted in $C$.

seems likely that these sequences are used to target the gene conversion apparently responsible for pilus antigenic variation, although specific recognition of these sequences by proteins cannot be ruled out.

Lichten et al. (1987) studied meiotic gene conversion and crossing over between dispersed homologous sequences in $S$. cerevisiae. They found no clear relationship between distance and recombination and suggested that specific loci may possess intrinsic probabilities of participating in meiotic exchange. It is also possible that recombination between distant loci was elevated above the level that would be expected on the basis of distance alone because of the presence of additional homologous sequences nearby (perhaps Ty elements).

A similar explanation may account for the results of Amstutz et al. (1985). They assayed meiotic nonallelic conversion in three tRNA genes in Schizosaccharomyces pombe and found that interchromosomal nonal- 


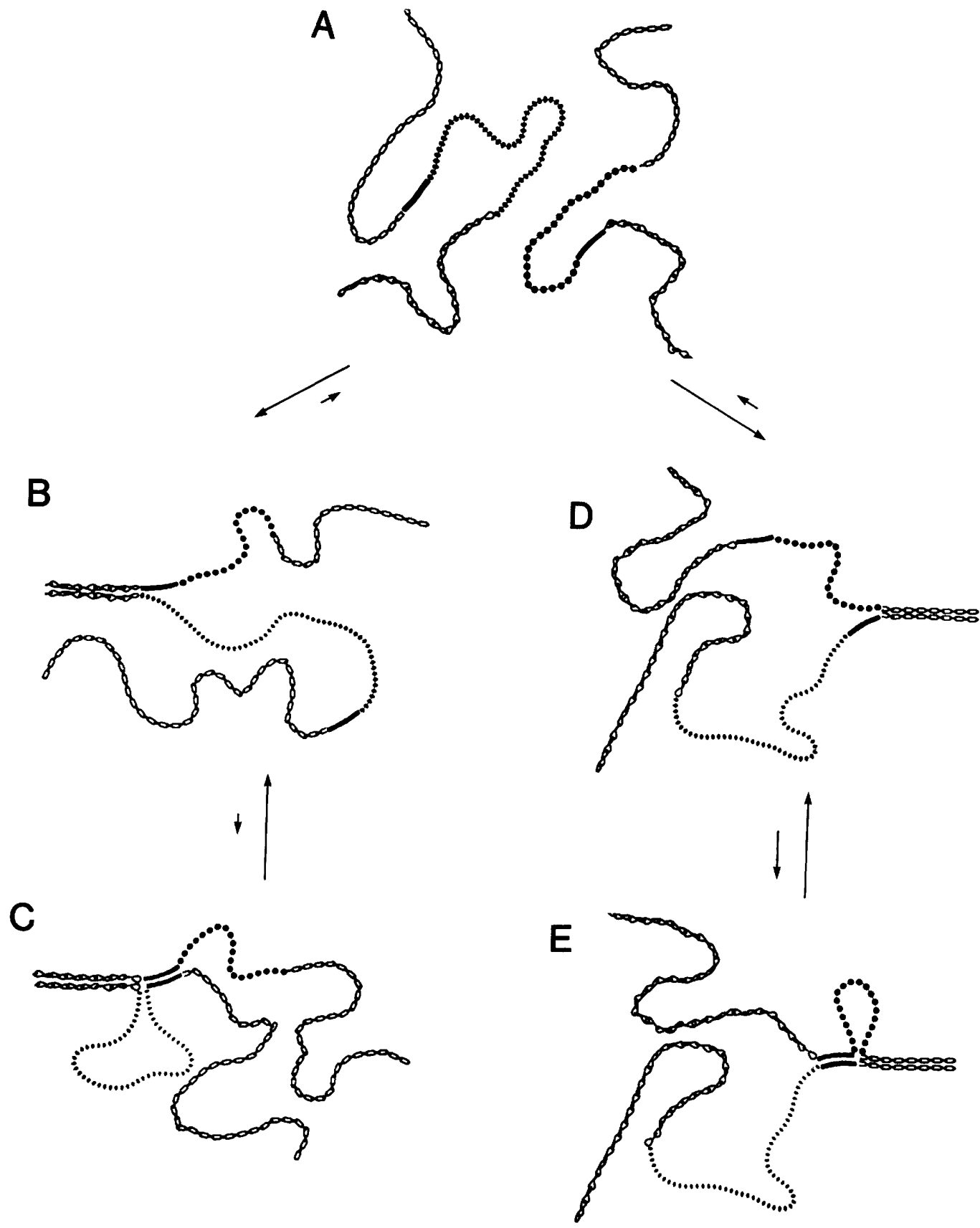

Figure 5. Probable steps in deletion formation in crosses with nonhomologous spacers. (A) Analogous to $A$ in Figs. 3 and 4 , except that unmatched strings of beads represent nonhomologous spacers. $(B$ and $C)$ Alignment in the T4 chromosome to the left of the repeats and spacers. (D and $E)$ Alignment in the T4 chromosome to the right of the repeats and spacers.

lelic gene conversion is $5-10$ times more common than the intrachromosomal event. It is possible that both pairs of interchromosomal conversions are stimulated by nearby homologous sequences. The data presented here for crosses with nonhomologous spacers suggest another explanation. In the intrachromosomal conversions, alignment in the region between the two genes keeps the two tRNA genes (repeats) apart. In interchromosomal conversion, the absence of this inhibition may explain the elevated conversion frequencies.
These examples demonstrate the generality of targeting. Bacteriophage T4 has proved an ideal experimental system in which to examine the phenomenon.

\section{Experimental procedures}

T4

All of the bacteriophage strains used in this study are mutant in the $I I I B$ gene. Mutations were engineered in the cloned $I I I B$ gene, as described below, and recombined into $\mathrm{T} 4$, as described 
Table 5. Sequences used in this study

A. Sequence of chromosome with left repeat and no additional insert. The repeats are either GC rich (as in pBSS27, see Table 6) or AT rich (pBSS33). (Y) A site at which the GC-rich repeat has $C$ and the AT-rich repeat has $T_{i}(\mathrm{R}) \mathrm{G}$ in the GC-rich repeat and A in the AT-rich repeat. Sau3A1 fragments can be inserted into the BamHI site. When necessary, the $X b a I$ site was filled in (see text).

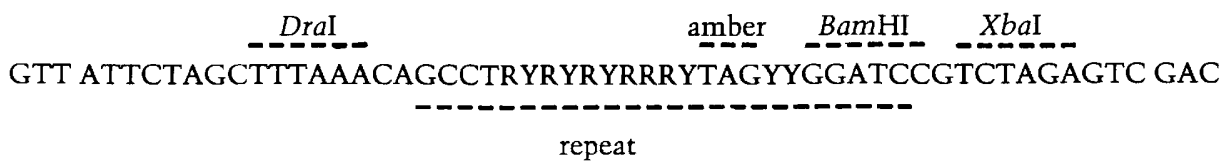

B. Sequence of chromosome with right repeat and no additional insert. The plasmid with the GC-rich repeat is pBSS32, and that with the AT-rich repeat is pBSS29. Sau3Al fragments can be inserted into the BglII site. When necessary, the BglII site was filled in (see text).

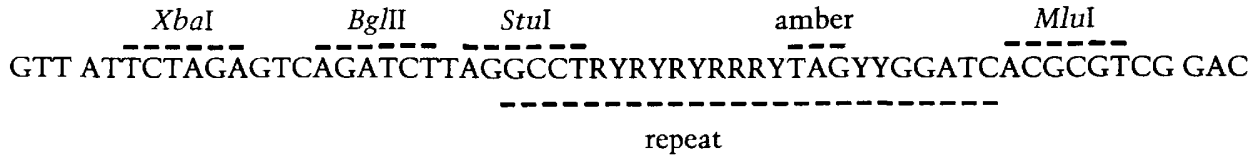

C. Sequence of the recombinant deletion. Both BamHI and BglII sites, as well as any fragments resident therein, are deleted.

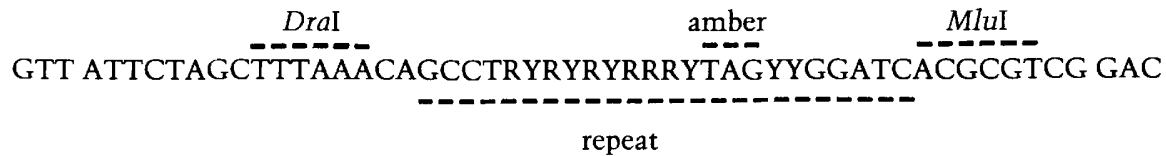

earlier (Singer and Westlye 1988). All of the strains used contain the deletion sa $\Delta 9$ (Depew et al. 1975) to compensate for the extra DNA inserted into the $r I I B$ gene. Neither deletion frequencies (Singer and Parma 1987) nor recombination frequencies (data not shown) are affected by sa $\Delta 9$.

The T4 recombination-defective alleles used are $\operatorname{amX} 11$, uvsX (from J.W. Drake); amYm, uvsY (from N.V. Hamlett); amC237, gene 39, amC5, gene 59, and amE727, gene 49 (all from W.B. Wood); and amB271, gene 46, and amE219, gene 61 (Singer et al. 1982). I crossed all of these alleles into the T4B genetic background before making double mutants with $r I I B$ mutations.

\section{Construction of rIIB mutations}

Each of the strains used for crosses has either a left or a right repeat. These sequences were inserted into the cloned $r I I B$ gene, as described earlier (Singer and Westlye 1988). Table 5 shows the sequences of the left and right repeats resident in the rIIB gene. The GTT-GAC sequence that flanks the inserts is the unique HincII site of $r I I B$; GTT and GAC are in-frame codons in the wild-type sequence. The repeats are rich in either $A$ : $T$ or $G$ : $C$ base pairs. In Table 5, $R$ represents bases that are $A$ in the AT-rich repeat and G in the GC-rich repeat; similarly, $\mathrm{Y}$ represents $\mathrm{T}$ and $\mathrm{C}$. Table 5 also shows the sequence of the pseudowild deletion, which is the recombinant scored in crosses.

Various spacer DNA fragments were inserted in the BamHI and BglII sites shown in Table 5 . The rIIB mutations constructed for this study are described in Table 6. Table 7 shows the strains used in each experiment.

The 332-bp Sau3Al fragment from $\mathrm{mp} 9$ (Messing and Vieira 1982) was purified as described (Singer and Westlye 1988). When inserted into the BamHI site of the plasmid with the left repeat, this fragment regenerates a $B a m H I$ site at either the left or the right edge, depending upon orientation of the insert. The plus orientation is defined as the one in which the BamHI site is at the left edge of the insert. When the 332-bp fragment is inserted into the $B g I I I$ site of the plasmid with the right repeat, it regenerates a BglII site. In the plus orientation, the BgIII site is at the right of the inserted spacer.
Table 6. Description of rIIB mutations used in this study

\begin{tabular}{|c|c|c|c|}
\hline \multirow[b]{2}{*}{$\begin{array}{l}\text { Allele } \\
\text { number }\end{array}$} & \multicolumn{2}{|c|}{ Repeat } & \multirow[b]{2}{*}{$\begin{array}{l}\text { Insert(s) } \\
\text { (bp) }\end{array}$} \\
\hline & $\begin{array}{l}\text { left or } \\
\text { right }\end{array}$ & $\begin{array}{l}\text { AT or } \\
\text { GC rich }\end{array}$ & \\
\hline 27 & left & GC & none \\
\hline 29 & right & AT & none \\
\hline 32 & right & GC & none \\
\hline 33 & left & $\mathrm{AT}$ & none \\
\hline 36 & right & $\mathrm{AT}$ & $332(-)$ \\
\hline 40 & right & $\mathrm{AT}$ & $332 i+1$ \\
\hline 56 & right & GC & $1698(-)$ \\
\hline 59 & left & GC & $1698(-)$ \\
\hline 61 & right & GC & $1698(+)$ \\
\hline 64 & left & $\mathrm{AT}$ & $332(-)$ \\
\hline 73 & left & GC & $332 i-1$ \\
\hline 74 & right & GC & $332(-)$ \\
\hline 75 & left & GC & $341 \mid+1$ \\
\hline 77 & right & GC & $341|+| 332|-|$ \\
\hline 78 & left & GC & $332 i+1$ \\
\hline 79 & left & AT & $332 \mid+1$ \\
\hline 80 & left & $\mathrm{AT}$ & $332|-1 \quad 79|+1$ \\
\hline 81 & left & GC & $332 \mid-1 \quad 79 i+1$ \\
\hline 82 & right & $\mathrm{AT}$ & $332 i+1 \quad 79 \mid+1$ \\
\hline 84 & right & $\mathrm{AT}$ & $79|+| 332|-|$ \\
\hline 88 & left & AT & $79 i+|332|+1$ \\
\hline 89 & left & GC & $79|+| 332 \mid+1$ \\
\hline 91 & right & GC & $79 i+|332|-\mid$ \\
\hline 92 & right & GC & $79(-|332|-1$ \\
\hline 98 & right & GC & $791+1$ \\
\hline 99 & right & GC & $79 i-1$ \\
\hline 101 & right & GC & $341+1$ \\
\hline 103 & left & GC & $79 i+1$ \\
\hline
\end{tabular}

The allele number indicates a sequence present in the plasmid (pBSS no.) or in T4 with the rII mutation (BSS no.). The inserts are indicated by size (in bp) and orientation only (see text for a more complete description). When more than one insert is indicated, the left-hand insert is also on the left in the chromosome, i.e., closer to rIIA. 
Table 7. Key to strains used in this study

A. Strains used in Table 1

\begin{tabular}{cc}
\hline Size of spacer $(\mathrm{bp})$ & Strains crossed \\
\hline 79 & $103 \times 98$ \\
332 & $73 \times 74$ \\
341 & $75 \times 101$ \\
1698 & $59 \times 56$ \\
\hline
\end{tabular}

B. Strains used in Table 2

\begin{tabular}{|c|c|c|}
\hline \multirow[b]{2}{*}{ Spacer size (bp) } & \multicolumn{2}{|c|}{ Strains with } \\
\hline & left repeat & right repeat \\
\hline- & & 32 \\
\hline 79 & 103 & 98 \\
\hline 332 & 73 & 74 \\
\hline 341 & 75 & 101 \\
\hline 411 & 81 & 91 \\
\hline 673 & & 77 \\
\hline 1698 & 59 & 61 \\
\hline
\end{tabular}

C. Strains used in opposite orientation crosses of Table 3

Base composition

of repeat

Size of spacer (bp)

Strains crossed

\begin{tabular}{lrr}
\hline GC rich & 79 & $103 \times 99$ \\
GC rich & 332 & $78 \times 74$ \\
GC rich & 1698 & $59 \times 61$ \\
AT rich & 332 & $79 \times 36$ \\
AT rich & 332 & $64 \times 40$ \\
\hline
\end{tabular}

D. Strains used in Table 4A

\begin{tabular}{|c|c|c|c|c|c|}
\hline \multirow{2}{*}{$\begin{array}{l}\text { Base } \\
\text { composition } \\
\text { of repeat }\end{array}$} & \multirow{2}{*}{$\begin{array}{l}\text { Size of spacer } \\
\text { (and interrupter) } \\
\text { (bp) }\end{array}$} & \multicolumn{2}{|c|}{ Same orientation crosses } & \multicolumn{2}{|c|}{ Opposite orientation crosses } \\
\hline & & $\begin{array}{l}\text { with } \\
\text { interrupter }\end{array}$ & $\begin{array}{l}\text { without } \\
\text { interrupter }\end{array}$ & $\begin{array}{l}\text { with } \\
\text { interrupter }\end{array}$ & $\begin{array}{l}\text { without } \\
\text { interrupter }\end{array}$ \\
\hline AT rich & $332(79)$ & $79 \times 82$ & $79 \times 40$ & $64 \times 82$ & $79 \times 36$ \\
\hline AT rich & $332(79)$ & $88 \times 40$ & $64 \times 36$ & $88 \times 36$ & $64 \times 40$ \\
\hline GC rich & $332(79)$ & & $73 \times 74$ & $89 \times 74$ & $78 \times 74$ \\
\hline GC rich & 79 (332) & $81 \times 98$ & $103 \times 98$ & $81 \times 99$ & $103 \times 99$ \\
\hline
\end{tabular}

E. Strains used in Table 4B

\begin{tabular}{|c|c|c|c|c|c|}
\hline \multirow{2}{*}{$\begin{array}{l}\text { Base } \\
\text { composition } \\
\text { of repeat }\end{array}$} & \multirow{2}{*}{$\begin{array}{l}\text { Size of spacer } \\
\text { (and interrupter) } \\
\text { (bp) }\end{array}$} & \multicolumn{2}{|c|}{ Same orientation crosses } & \multicolumn{2}{|c|}{ Opposite orientation crosses } \\
\hline & & $\begin{array}{l}\text { with } \\
\text { interrupter }\end{array}$ & $\begin{array}{l}\text { without } \\
\text { interrupter }\end{array}$ & $\begin{array}{l}\text { with } \\
\text { interrupter }\end{array}$ & $\begin{array}{l}\text { without } \\
\text { interrupter }\end{array}$ \\
\hline AT rich & $332(79)$ & $64 \times 84$ & $79 \times 40$ & $79 \times 84$ & $79 \times 36$ \\
\hline AT rich & $332(79)$ & $80 \times 36$ & $64 \times 36$ & $80 \times 40$ & $64 \times 40$ \\
\hline GC rich & $332(79)$ & $73 \times 92$ & $73 \times 74$ & $78 \times 92$ & $78 \times 74$ \\
\hline GC rich & $79(332)$ & $89 \times 98$ & $103 \times 98$ & $89 \times 99$ & $103 \times 99$ \\
\hline
\end{tabular}

When crosses are indicated, the strain shown on the left has a left repeat and vice versa.

Strains used in same orientation crosses in Table 3 are as shown in Table 1 . The strains used for the same orientation crosses with AT-rich repeats are $64 \times 36$ and $79 \times 40$.

A 79-bp Sau3AI fragment that derives from bacteriophage $\lambda$ (Daniels et al. 1983) was cut out of a 1914-bp EcoRI-HindIII fragment (generously provided by T.D. Schneider) and purified as before. The 79-bp fragment was inserted into the BamHI (Table 5A) and $B g I I I$ (Table $5 \mathrm{~B}$ ) sites of the plasmids that either do or do not contain a 332-bp fragment. Here again, inserting this fragment into a construct with a left repeat regenerates a
BamHI site; the plus orientation is defined as the orientation that has BamHI on the left edge of the insert. Similarly, inserting the 79-bp fragment into the BgIII site of a construct with a right repeat regenerates a $B g l I I$ site, on the right in the plus orientation. For example, pBSS 84 was created by cutting pBSS36 with BglII, treating with phosphatase, and ligating in the presence of purified 79-bp fragment. The orientation of the 
79-bp fragment was determined by restriction analysis.

The 1698-bp insert is a Sau3Al fragment derived from $\mathrm{mp} 9$. When inserted into the BgIII site of a construct with a right repeat, it regenerates one BgIII site. pBSS61 has a BgIII site on the left of the insert, and pBSS56 has a BgIII site at the right. The orientation of the 1698-bp fragment in pBSS59 was ascertained by the asymmetrically situated SnaBI site.

The 34l-bp insert is derived from the $\beta$-lactamase gene of pUC8 (Messing and Vieira 1982). The plus orientation has a BglII site on the right when the fragment is inserted in pBSS101. An asymmetrically placed BgII site was used to determine the orientation of the fragment in pBSS75.

Some of the constructs were initially pseudo-wild when re-

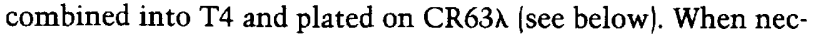
essary, the reading frame of the left repeat constructs was changed by cutting with $X b a I$ (see Table 5), filling in with DNA polymerase I, Klenow fragment (from New England BioLabs), in the presence of all four deoxyribonucleotide triphosphates, and ligating. This generated pBSS78, pBSS79, and pBSS103. The identical procedure with the BgIII site yielded pBSS101.

E. coli

Lysates were made on CR63 (Signer et al. 1965) or Bb (Karam and Barker 1971).

As shown in Table 5, the recombinant deletion that is scored in crosses has an in-frame amber mutation. Hence, crosses were plated on the amber-suppressing host CR63 to measure total

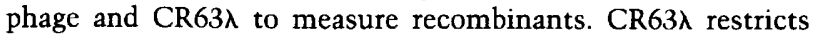
the parental phage but not the recombinant deletion progeny. Crosses with rec ${ }^{-}$backgrounds were performed on NapIVS ${ }^{R}$ (Nelson et al. 1982). The rest of the crosses were performed on NapIVSm ${ }^{\mathrm{R}}$, CR63, or Bb. All hosts yield comparable recombination frequencies.

\section{Crosses}

Cells were grown in $\mathrm{H}$ broth (Steinberg and Edgar 1962) to $2 \times 10^{8} / \mathrm{ml}$ and infected with an moi 5 of each parent. Selfcrosses were performed routinely to determine the reversion frequency under the growth conditions of the cross. The data shown are the averages ( \pm S.E.M.) of at least three crosses performed using independent lysates.

\section{Acknowledgments}

It is a pleasure to acknowledge the proficient technical assistance of Jane Westlye. I thank Shelley Beckmann, Sean Eddy, Larry Gold, Peter Gauss, Dave Parma, and Sid Shinedling for stimulating discussion and thoughtful reading of the manuscript. I am grateful for helpful conversations with Shelley Esposito, Paul Hagerman, Doug Irvine, Mike Liskay, Tom Petes, Shirleen Roeder, John Roth, Judy Ruckman, and John Wilson. I am also grateful to Kathy Piekarski for typing the tables and to Diane Lorenz, Larry Harwood, and Andrea Olsheskie for preparing the figures. This work was funded by $\mathrm{Na}$ tional Institutes of Health grant GM-28634.

\section{References}

Albertini, A.M., M. Hofer, M.P. Calos, and J.H. Miller. 1982. On the formation of spontaneous deletions: The importance of short sequence homologies in the generation of large deletions. Cell 29: 319-328.

Amstutz, H., P. Munz, W.-D. Heyer, U. Leupold, and J. Kohli.
1985. Concerted evolution of tRNA genes: Intergenic conversion among three unlinked serine tRNA genes in S. pombe. Cell 40: 879-886.

Bianchi, M., C. DasGupta, and C.M. Radding. 1983. Synapsis and the formation of paranemic joints by E. coli RecA protein. Cell 34: 931-939.

Christiansen, G. and J. Griffith. 1986. Visualization of the paranemic joining of homologous DNA molecules catalyzed by the RecA protein of Escherichia coli. Proc. Natl. Acad. Sci. 83: 2066-2070.

Daniels, D.L., J.L. Schroeder, W. Szybalski, F. Sanger, A.R. Coulson, G.F. Hong, D.F. Hill, G.B. Petersen, and F.R. Blattner. 1983. Complete annotated lambda sequence. In Lambda II led. R.W. Hendrix, J.W. Roberts, F.W. Stahl and R.A. Weisberg), pp. 519-676. Cold Spring Harbor Laboratory, Cold Spring Harbor, New York.

DasGupta, U., K. Weston-Hafer, and D.E. Berg. 1987. Local DNA sequence control of deletion formation in Escherichia coli plasmid pBR322. Genetics 115: 41-49.

Depew, R.E., T.J. Snopek, and N.R. Cozzarelli. 1975. Characterization of a new class of deletions of the D region of the bacteriophage T4 genome. Virology 64: 144-152.

Doermann, A.H. and D.H. Parma. 1967. Recombination in bacteriophage T4. I. Cell. Comp. Physiol. (suppl. 1, no.2) 70:147-164.

Dvořák, J., D. Jue, and M. Lassner. 1987. Homogenization of tandemly repeated nucleotide sequences by distance-dependent nucleotide sequence conversion. Genetics 116: 487 498.

Efstratiadis, A., J.W. Posakony, T. Maniatis, R.M. Lawn, C. O'Connell, R.A. Spritz, K. DeRiel, B.G. Forget, S.M. Weissman, J.L. Slightom, A.E. Blechl, O. Smithies, F.E. Baralle, C.C. Shoulders, and N.J. Proudfoot. 1980. The structure and evolution of the human $\beta$-globin gene family. Cell 21: $653-668$.

Ernst, J.F., J.W. Stewart, and F. Sherman. 1982. Formation of composite iso-cytochromes $c$ by recombination between non-allelic genes of yeast. I. Mol. Biol. 161: 373-394.

Flavell, R.A., H. Allen, L.C. Burkly, D.H. Sherman, G.L. Waneck, and G. Widera. 1986. Molecular biology of the H-2 histocompatibility complex. Science 233: 437-447.

Geliebter, J., R.A. Zeff, D.H. Schulze, L.R. Pease, E.H. Weiss, A.L. Mellor, R.A. Flavell, and S.G. Nathenson. 1986. Interaction between $K^{b}$ and $Q 4$ gene sequences generates the $K^{b m b}$ mutation. Mol. Cell. Biol. 6: 645-652.

George, D.G., L.-S.L. Yeh, and W.C. Barker. 1983. Unexpected relationships between bacteriophage lambda hypothetical proteins and bacteriophage T4 tail-fiber proteins. Biochem. Biophys. Res. Commun. 115: 1061-1068.

Gonda, D.K. and C.M. Radding. 1986. The mechanism of the search for homology promoted by recA protein: Facilitated diffusion within nucleoprotein networks. I. Biol. Chem. 261: 13087-13096.

Haas, R. and T.F. Meyer. 1986. The repertoire of silent pilus genes in Neisseria gonorrhoeae: Evidence for gene conversion. Cell 44: 107-115.

Hagerman, P.J. 1981. Investigation of the flexibility of DNA using transient electric birefringence. Biopolymers 20: $1503-1535$.

Heyer, W.-D., P. Munz, H. Amstutz, R. Aebi, C. Gysler, P. Schuchert, P. Szankasi, U. Leupold, J. Kohli, V. Ganulin, and D. Soll. 1986. Inactivation of nonsense suppressor transfer RNA genes in Schizosaccharomyces pombe: Intergenic conversion and hot spots of mutation. J. Mol. Biol. 188: 343353.

Howard-Flanders, P., S.C. West, and A. Stasiak. 1984. Role of 
RecA protein spiral filaments in genetic recombination. $\mathrm{Na}$ ture 309: 215-220.

Karam, J.D. and B. Barker. 1971. Properties of bacteriophage T4 mutants defective in gene 30 (deoxyribonucleic acid ligase) and the rII gene. $/$. Virol. 7: 260-266.

Lichten, M., R.H. Borts, and J.E. Haber. 1987. Meiotic gene conversion and crossing over between dispersed homologous sequences occurs frequently in Saccharomyces cerevisiae. Genetics 115: 233-246.

McGavin, S. 1971. Models of specifically paired like (homologous) nucleic acid structures. J. Mol. Biol. 55: 293-298.

Messing, J. and J. Vieira. 1982. A new pair of M13 vectors for selecting either DNA strand of double-digest restriction fragments. Gene 19: 269-276.

Michel. C.J., B. Jacq, D.G. Arguès, and T.A. Bickle. 1986. A remarkable amino acid sequence homology between a phage T4 tail fiber protein and ORF314 of phage lambda located in the tail operon. Gene 44: 147-150.

Nelson, M.A., M. Ericson, L. Gold, and J.F. Pulitzer. 1982. The isolation and characterization of TabR bacteria: Hosts that restrict bacteriophage T4 rII mutants. Mol. Gen. Genet. 188: $60-68$.

Pays, E. 1985. Gene conversion in trypanosome antigenic variation. Prog. Nucleic Acid Res. Mol. Biol. 32: 1-26.

Powers, P.A. and O. Smithies. 1986. Short gene conversions in the human fetal globin gene region: A by-product of chromosome pairing during meiosis? Genetics 112: 343-358.

Reynaud, C.-A., V. Anquez, H. Grimal, and J.-C. Weill. 1987. A hyperconversion mechanism generates the chicken light chain preimmune repertoire. Cell 48: $379-388$.

Riddles, P.W. and I.R. Lehman. 1985. The formation of paranemic and plectonemic joints between DNA molecules by the RecA and single-stranded DNA-binding proteins of Escherichia coli. J. Biol. Chem. 260: 165-169.

Riede, I. 1986. T-even type phages can change their host range by recombination with gene 34 (tail fibre) or gene 23 (head). Mol. Gen. Genet. 205: 160-163.

Riede, I., M.-L. Eschbach, and U. Henning. 1985. Presence of DNA, encoding parts of bacteriophage tail fiber genes, in the chromosome of Escherichia coli K-12. I. Bacteriol. 163: 832-836.

Roeder, G.S., M. Smith, and E.J. Lambie. 1984. Intrachromosomal movement of genetically marked Saccharomyces cerevisiae transposons by gene conversion. Mol. Cell. Biol. 4: $703-711$.

Schutte, B.C. and M.M. Cox. 1987. Homology-dependent changes in adenosine $5^{\prime}$-triphosphate hydrolysis during recA protein promoted DNA strand exchange: Evidence for long paranemic complexes. Biochemistry 26: 5616-5625.

Shinedling, S.T., B.S. Singer, M. Gayle, D. Pribnow, E. Jarvis, B. Edgar, and L. Gold. 1987. Sequences and studies of bacteriophage T4 rII mutants. J. Mol. Biol. 195: 471-480.

Signer, E.R., J.R. Beckwith, and S. Brenner. 1965. Mapping of suppressor loci in Escherichia coli. J. Mol. Biol. 14: 153166.

Singer, B.S. and D. Parma. 1987. Observations on terminal redundancy. T4 News 1: 6-7.

Singer, B.S. and J. Westlye. 1988. Deletion formation in bacteriophage T4. J. Mol. Biol. 202: 233-243.

Singer, B.S., L. Gold, P. Gauss, and D.H. Doherty. 1982. Determination of the amount of homology required for recombination in bacteriophage T4. Cell 31: 25-33.

Slightom, J.L., A.E. Blechl, and O. Smithies. 1980. Human fetal $\mathrm{G}_{\gamma}-$ and Ay-globin genes: Complete nucleotide sequences suggest that DNA can be exchanged between these duplicated genes. Cell 21: 627-638.
Steinberg, C.M. and R.S. Edgar. 1962. A critical test of a current theory of genetic recombination in bacteriophage. Genetics 47: $187-208$.

Wilson, J. 1979. Nick-free formation of reciprocal heteroduplexes: A simple solution to the topological problem. Proc. Natl. Acad. Sci. 76: 3641-3645. 


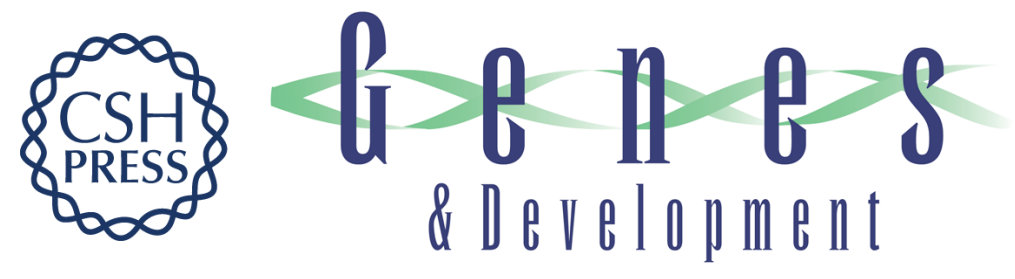

\section{On the role of homologous sequences in chromosomal rearrangements.}

\section{B S Singer}

Genes Dev. 1988, 2:

Access the most recent version at doi:10.1101/gad.2.12b.1800

References This article cites 40 articles, 14 of which can be accessed free at: http://genesdev.cshlp.org/content/2/12b/1800.full.html\#ref-list-1

License

Email Alerting

Service

Receive free email alerts when new articles cite this article - sign up in the box at the top right corner of the article or click here.

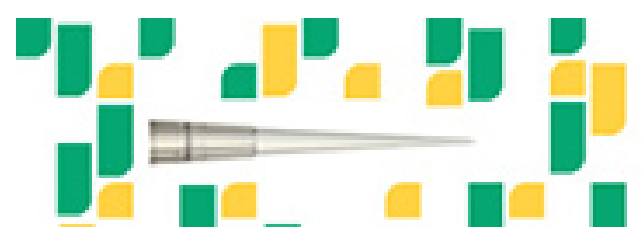

Focused on your science.

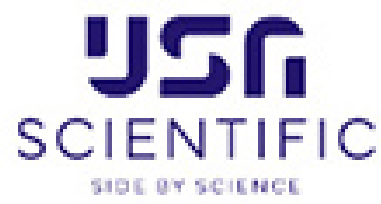

Copyright (c) Cold Spring Harbor Laboratory Press 